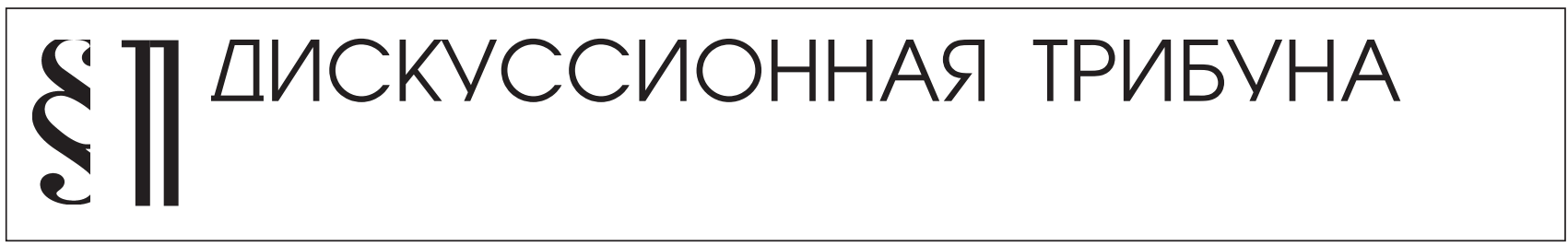

Кретов В.В.

\title{
О НЕОБХОДИМОСТИ СОВЕРШЕНСТВОВАНИЯ ФЕДЕРАЛЬНОГО ЗАКОНА «ОБ АВТОМОБИЛЬНЫХ ДОРОГАХ И ДОРОЖНОЙ ДЕЯТЕЛЬНОСТИ...»
}

\begin{abstract}
Аннотация: Предметом исследования является Федеральный закон "Об автомобильных дорогах и дорожной деятельности в Российской Федерачии.." №257-Ф3 от 8.11.20072., как основа законодательства Российской Федерации об автомобильных дорогах и дорожной деятельности. Объектом исследования являются правовые нормы, содержащиеся в Законе и регулирующие основы функиионирования дорожного хозяйства страны. Особое внимание уделено предложениям, по совершенствованию содержащихся в Законе норм, путем их редактирования, а также включения в закон дополнительных статей, позволяющих ликвидировать пробель в законодательстве об автомобильных дорогах и дорожной деятельности. При решении поставленных задач, были использованы такие методы исследования как системный, сравнительно-правовой и формально-логический. В статье использованы как общенаучные методы анализа применяемые на четырех уровнях исследования: описание, классификация, объяснение, критика результатов исследования, так и специиальные - сравнительно-правовой, исторический и другие. Научная новизна статьи заключается в том, что впервые проанализирована основа законодательства Российской Федераиии об автомобильных дорогах и дорожной деятельности, выявлены основные недостатки и пробелы права, а также разработаны меры по устранению недостатков, тормозящих развитие дорожного хозяйства страны. Предлагаемые изменения позволят существенно конкретизировать нормы, регулирующие использование автомобильных дорог и осуществление дорожной деятельности, а также установить ответственность органов исполнительной власти и их глав, недобросовестно выполняющих свои обязанности.
\end{abstract}

Ключевые слова: Дорожное хозяйство, дороги, дорожная деятельность, дорожное законодательство, органы управления, пользователи дорог, финансирование, обязанности, физические лиза, юридические лица. Abstract: The subject of this research is the Federal Law "On the Roads and Road Activities in the Russian Federation..." No. 257-FZ from November 8, 2007, as the foundation of legislation of the Russian Federation on roads and road activities. The object of the research is the legal norms, contained in the law, that regulate the core functionality of the roads and driving. A special attention is given to the proposition on improving these legal norms by changing them, as well as introducing additional articles that would allow eliminating the gaps in legislation on roadways and road activities. The scientific novelty consists in the fact that the author is first to analyze the foundation of the legislation of the Russian federation on roads and road activities, detects the key flaws and gaps in the law, and devises measures for remedying the imperfections that impede the development of the road system. The proposed changes allow a significant concretization of the norms that regulate the use of roads, as well setting the responsibility for the authorities of executive branches and their leadership that are not performing their duties.

Keywords: Financing, road users, operating control, road legislation, road activities, roads, road system, duty, individuals, legal entities. 
DOI: $10.7256 / 1811-9018.2015 .8 .15917$

При цитировании этой статьи сноска на ооі обязательна

\section{Право и политика 8 (188) 2015}

Д о принятия в 2007 году Федерального закона «Об автомобильных дорогах и дорожной деятельности...» №257-Ф3 (далее Закон) дорожное законодательство в Российской Федерации фактически отсутствовало. В результате чего, не решались многие вопросы, связанные с обеспечением страны необходимой сетью автомобильных дорог. Принятый Закон был направлен в первую очередь на устранение пробелов в действовавшем правовом регулировании дорожного хозяйства страны и создание юридической основы системного государственного регулирования общественных отношений в сфере дорожной отрасли.

В то же время, выполненный анализ содержания основных глав Закона позволяет сделать вывод о необходимости их совершенствования, путем устранения выявленных в имеющемся тексте недостатков, включения дополнений в имеющиеся статьи, а также принятия дополнительных статей.

В частности, имеется целый ряд замечаний по первой главе Закона, содержащей общие положения и определяющей сферы его действия. В главе сформулированы основные цели Закона, направленные на определение основ функционирования автомобильных дорог, осуществление дорожной деятельности в интересах пользователей, обеспечение их развития, сохранности и улучшение состоянии, совершенствование государственного управления дорожной деятельностью, содействие внедрению эффективных технологий и стандартов. Следует отметить, что цели, определяющие необходимость совершенствования государственного управления в области дорожной деятельности, а также обеспечение развития, улучшения состояния и сохранности дорог, являются наиболее важными для государства и пользователей и в первую очередь требуют четкости и конкретности изложения, что не всегда обеспечивается положениями Закона.

В связи с этим, ряд формулировок основных целей и понятий Закона, изложенных в ст.2 и ст.3 первой главы предлагается откорректировать. В частности предлагается: изменить содержание понятия «дорожная деятельность», под которым в Законе предлагается понимать деятельность по проектированию, строительству, реконструкции, капитальному ремонту, ремонту и содержанию автомобильных дорог. Это понятие является составной частью одной из основных целей (п.2) - совершенствование государственного управления в области дорожной деятельности.

Во-первых, необходимо отметить, что к основным вопросам дорожной деятельности, кроме указанных в п.6 ст.3 ( проектирование, строительство, реконструкция, капитальный ремонт и содержание), необходимо дополнительно отнести - управление дорожным хозяйством и научные исследования в области дорожного хозяйства.

Во-вторых под дорожной деятельностью, предлагается понимать деятельность по обеспечению развития, совериенствования и поддержания сети автомобильньх дорог общего пользования в состоянии, соответствующем требованиям действующих нормативно-технических документов, с иелью удовлетворения спроса пользователей дорог. Такое определение является более четким и конкретным.

С учетом того, что стране не хватает минимум миллиона километров автодорог, а состояние почти 70\% существующих не отвечает нормативным требованиям и нуждаются в ремонте [ 1 ], вполне обоснованно можно говорить о необходимости корректировки и конкретизации цели, изложенной в п.3 ст.2 Закона, направленной на «обеспечение сохранности и развития автомобильных дорог, улучшение их технического состояния», не являющейся конкретной и четкой.

Предлагается следующая формулировка этой цели - обеспечение развития, совершенствования $и$ поддержании сети автомобильньх дорог в состоянии, соответствующем требованиям действующих нормативно-технических документов.

В сравнении с изложенной в Законе, предлагаемая формулировка вводит дополнительное направление - «совершенствование сети дорог» т.е. улучшение качества существующих дорог (реконструкция, модернизация) и конкретизирует вопрос с техническим состоянием - дороги должны соответствовать требованиям нормативно-технических документов.

При этом, в связи с отсутствием в ст.3 Закона целого ряда важных, базовых для дорожного хозяйства определений, дополнительно предлагается ввести в ст.3 следующие основные понятия:

- сеть автомобильных дорог: под сетью автомобильных дорог предлагается понимать совокупность автомобильных дорог различного значения, связывающчих объекты различных секторов экономики и социиальной сферы в единую систему и обеспечиваюших безопасное, бесперебойное, с расчетными скоростями движение по ним автотранспорта.

Более подробное обоснование необходимости применения в Законе термина «сеть автомобильных дорог» приведено ниже;

- развитие сети автомобильных дорог: под развитием сети автомобильных дорог предлагается понимать-строительство новых автомобильньх дорог 
различного значения с ичелью обеспечения безопасной и бесперебойной связи между объектами различных секторов экономики и соичильной сферы и объединение их в единую систему;

- совершенствование сети автомобильных дорог: под совершенствованием сети автомобильных дорог предлагается понимать улучшение технических характеристик отдельных автомобильных дорог (входящих в сеть дорог) с ичелью удовлетворения возрастающего спроса пользователей в безопасном, бесперебойном, с расчетными скоростями движении транспорта по таким дорогам;

- поддержание сети автомобильных дорог в состоянии отвечающем требованиям действующих нормативно-технических документов: под поддержанием сети автомобильных дорог в состоянии, отвечающем требованиям действующих нормативно-технических документов, предлагается понимать комплекс мер по обеспечению сохранности автомобильных дорог от противоправных действий пользователей дорог, иных физических и юридических лии и соблюдению органами, осущуествляющими дорожную деятельность, своевременного и качественного выполнения комплекса работ по содержанию, ремонту, и капитальному ремонту автодорог, в соответствии с действующими нормативно-техническими документами.

Требует серьезной доработки формулировка цели, изложенная в п.4, заключающаяся в «содействии внедрению перспективных технологий и стандартов в области дорожной деятельности». Во-первых, примененный в п.4 ст.2 Закона термин «содействие» при определении цели, связанной с перспективами в сфере дорожной деятельности, реально не будет способствовать развитию дорожной науки, что уже подтверждено имеющейся практикой. Во-вторых, как показывает та же практика, отсутствие в Законе цели, определяющей обязательность проведения научных исследований в области дорожной деятельности спровоцирует не только развал отраслевой науки, но и , как следствие, снижение эффективности функционирования всего дорожного хозяйства страны.

В связи с этим предлагается следующая формулировка этой цели - обеспечение проведения научных исследований и внедрения наиболее эффективных научных результатов и стандартов в области дорожной деятельности.

Постановка такой цели, обязывающей проведение и внедрение научных исследований, будет способствовать развитию отраслевой науки, разработке и внедрению не только новых, эффективных технологий, но и конструкций, дорожно-строительных материалов, методов организации работ и т.д. Как показывает организационно-правовой опыт зарубежных стран, [2] развитие дорожной науки в значительной мере способствует снижению стоимости дорожных работ, ресурсосбережению, продлению сроков службы дорожных конструкций, и в целом - повышению эффективности функционирования дорожного хозяйства.

В статье 3 приведены основные понятия, используемые в Законе, в том числе, дано такое основополагающее понятие как «автомобильная дорога». В п.1 определено, что автомобильная дорога является объектом транспортной инфраструктуры, предназначенным для движения транспортных средств, включающим в себя земельные участки и расположенные на них конструктивные дорожные элементы.

Более адекватными сути рассматриваемого объекта могло бы быть понятие, определяюшее автомобильную дорогу как имущественный комплекс, предназначенньй для безопасного, бесперебойного, с расчетныли скоростями движения транспортных средств, отвечающий экономическим и сочиальным потребностям страны и отдельных пользователей. Такое понятие определяет как необходимость дальнейшее раскрытие в Законе основных положений и дополнительных понятий, определяющих:

- «имущественный комплекс» как совокупность дороги, зданий, сооружений и т.д., связанных между собой в единое целое, обеспечивающее реализацию функционального назначения дороги;

- необходимость обоснования эффективности инвестиций, направляемых на развитие автомобильных дорог, сохранность имущества, развития и внедрения инноваций, то есть всего, что повышает эффективность функционирования комплекса;

- бесперебойность безопасность и возможность движения транспорта с расчетными скоростями по автомобильной дороге, как результата осуществления дорожной деятельности.

Необходимо отметить, что таких положений и понятий в Законе нет.

Вторым основополагающим понятием Закона является «дорожная деятельность». Дорожной деятельностью в Законе предлагается считать деятельность по проектированию, строительству, реконструкции, капитальному ремонту, ремонту и содержанию автодорог. Необходимо заметить, что по сути своей, это не определение дорожной деятельности, а далеко не полный перечень работ, относящихся к дорожной деятельности. Не останавливаясь на рассмотрении 
DOI: $10.7256 / 1811-9018.2015 .8 .15917$

При цитировании этой статьи сноска на ооі обязательна

\section{Право и политика 8 (188) 2015}

социально-экономических систем, в которых дороги формируют важную системообразующую инфраструктуру, отметим только то, что дорожная деятельность должна обеспечивать не только сохранение и создание в них новых связей (строительством, ремонтом и содержанием автодорог), но, одновременно и снижение удельных энергозатрат, обеспечение движения транспортных средств с расчетными скоростями и безопасности дорожного движения. Не требует доказательства то, что без науки, грамотного, профессионального управления, эффективно вести дорожную деятельность невозможно. Известно [3], что деятельность являющаяся формой активного отношения человека к окружающему миру, предполагает целесообразное его изменение и преобразование. Деятельность включает в себя цель, средство, результат и сам процесс деятельности. Иными словами неотъемлемой характеристикой деятельности является ее осознанность. Исходя из изложенного, понятие дорожной деятельности сформулировано и приведено выше.

Действующий Закон требует корректировки и по целому ряду других статей. Хотелось бы подробнее остановиться на таком важном, но отсутствующем в Законе понятии как «сеть автомобильных дорог». Автомобильные дороги России представляют собой сеть, формирующуюся автомобильными дорогами различного значения и прав собственности. Учитывая системообразующую роль автомобильных дорог, под сетью автомобильных дорог предлагается понимать совокупность автомобильных дорог различного значения, связывающих объекты различных секторов экономики и социальных сфер в единую систему. Объекты секторов экономики и социальной сферы, находясь в определенных взаимоотношениях и связях между собой, образуют определенную целостность, именующуюся социально-экономической системой. Согласно гл. 3,8 Конституции РФ и Федерального закона «Об общих принципах организации местного самоуправления в Российской Федерации», в стране имеется три уровня иерархически взаимосвязанных социально-экономических систем - Российской Федерации , субъектов РФ и муниципальных образований. При этом социально-экономические системы каждого из иерархических уровней имеют в собственности и развивают свои сети автомобильных дорог, что в корне противоречит концепции единой сети автомобильных дорог страны.

Одной из важнейших проблем сегодняшнего дня, решение которой не нашло отражение в Законе, явля- ется необходимость скоординированного развития и совершенствования автомобильных дорог различной формы собственности, как единой сети автомобильных дорог. При этом под координацией понимается не только рациональное начертание структуры сети, обоснование параметров и капитальности ее основных звеньев, но и решение интересов различных пользователей дорог, кооперация сил и средств государства и бизнеса в строительстве, реконструкции, сервисном обустройстве дорог, формировании единой дорожной политики, в том числе направленной на развитие науки, образования, дорожного машиностроения, стройиндустрии и т.д. Однако ст. 6. 11, 12, 13 Закона определяют разделение направлений развития автомобильных дорог, исходя из их собственности, между органами государственной власти РФ, субъектами РФ и органами местного самоуправления. При этом, в федеральном законодательстве нет положений, обязывающих вести согласованное развитие сети автомобильных дорог. В ст. 14 Закона планирование дорожной деятельности, включая строительство, автомобильных дорог, развитие дорожной сети, определяется на основании документов территориального планирования, подготовка и утверждение которых осуществляется в соответствии с Градостроительным кодексом Российской Федерации (ГК РФ). В рамках формирования сети автомобильных дорог в документах территориального планирования, определяемых ГК РФ, рассматриваемая проблема представлена документами территориального планирования РФ, субъектов РФ и муниципальных образований.

Выполненный анализ Закона показывает, что за развитие сети дорог страны, как единого целого, в России никто не несет ответственности. И это при том, что именно сеть автомобильных дорог, как важнейшая системообразующая инфраструктура, должна неразрывно связывать между собой объекты секторов экономики и социальной сферы, обеспечивая тем самым целостность государства и его экономическое развитие.

Необходимо обратить внимание и на понятие «пользователи дорог». В п.8 ст.3 Закона пользователями дорог определены физические и юридические лица, использующие автомобильные дороги в качестве участников дорожного движения.

Корректность данного определения так же вызывает вопрос. Может ли быть участником движения юридическое лицо, т.е. может ли участвовать в движении « ...организация, имеющая в собственности, хозяйственном ведении или оперативном управлении обособленное имущество» (в нашем случае автомо- 
биль)? П.8 ст.3 правильнее было бы изложить, после слов «...физические и юридические лица, использующие автомобильные дороги» продолжить - для проезда по ним принадлежащих им автотранспортных средств...» и далее по тексту.

В то же время необходимо отметить, что ряду используемых и важнейших для отрасли терминов, таких как «автодорожное хозяйство», «административно-правовое регулирование дорожного хозяйства», «сохранность дорог», «управление дорожным хозяйством с привлечением пользователей дорог» в Законе определений не дано, а отдельные из сформулированных понятий не являются оптимальными, четко отражающими суть рассматриваемого объекта.

Так : - в п.4 ст.3, определяющем понятие «производственные объекты», к последним отнесены сооружения, используемые при капитальном ремонте, ремонте и содержании автомобильных дорог и не учтены сооружения, используемые при строительстве и реконструкции автомобильных дорог. Предлагается дополнить это определение, после слов «... - сооружения, используемые...» включив «при строчтельстве и реконструкции» и далее по тексту;

- под «содержанием автомобильной дороги» (в п.12 ст.3) предлагается понимать комплекс работ по поддержанию надлежащего технического состояния автомобильной дороги и т.д.

Представленную в Законе формулировку предлагается изменить и изложить в следующем виде: после слов «... по поддержанию...» включить «автомобильных дорог в состоянии, соответствующем требованиям нормативно-технических документов» и далее по тексту, т.е. ставится конкретная задача - дороги должны находиться в состоянии, соответствующем требованиям нормативно технических документов, в то время как понятие - поддержание в надлежащем состоянии не является конкретным, что в конечном итоге и отражается на состоянии дорог страны.

Статья 4 Закона определяет что законодательство об автомобильных дорогах и дорожной деятельности Российской Федерации основывается на Конституции Российской Федерации, и состоит из настоящего закона, иных федеральных законов и принимаемых в соответствии с ними законов субъектов Российской Федерации.

Необходимо отметить, что законодательство об автомобильных дорогах и дорожной деятельности находится на начальном пути своего развития и требует своего совершенствования. Подтверждением этому является то, что до сих пор в действующих законах не решены такие основополагающие вопросы, как:
- обеспечение адекватного финансирования дорожного хозяйства;

- обеспечение эффективного управлении дорожным хозяйством, в т.ч. за счет привлечения к управлению дорожным хозяйством пользователей дорог, наиболее заинтересованных в улучшении состояния дорог;

- обеспечение конкретной ответственности руководителей дорожного хозяйства за развитие и состояние автодорожной сети и т.д.

Законодательство об автодорогах и дорожной деятельности должно быть значительно расширено с включением в него положений, обеспечивающих э $\phi$ фективное решение указанных выше вопросов.

Необходимо отметить, что в статье 5 Закона, посвященной классификации автомобильных дорог, также имеются неточности, так в п.14.4 и п.16.4, характеризующих отличительные черты автомагистралей и скоростных автомобильных дорог, говорится о том, что на их проезжих частях запрещены стоянки транспортных средств. Выполненный анализ показывает, что это не является отличительной чертой данных дорог, т.к. действующими ПДД уже закреплен запрет на осуществление стоянок на проезжей части всех автомобильных дорог общего пользования.

Так же не является отличительной чертой автомагистралей наличие площадок для стоянок транспортных средств и мест отдыха, т.к. на большинстве дорог 2-й, 3-ей и 4-й технических категорий они уже давно имеются.

В статье 6 Закона, посвященной вопросам собственности, определено, что автодороги могут находиться в федеральной собственности, собственности субъектов РФ, муниципальной собственности, а также в собственности физических и юридических лиц и устанавливаются критерии отнесения дороги к тому или иному виду собственности, но не затронута специфика передачи дорог из одной формы собственности в другую, что позволяет говорить о нерешенности достаточно сложного вопроса.

Необходимо отметить, что в немецком законодательстве [4] при передаче автодороги из одной собственности в другую, передающая сторона в обязательном порядке выполняет комплекс необходимых дорожных работ и выдает гарантию того, что на дороге выполнены все предусмотренные нормами, регламентированные работы и передаваемая дорога соответствует нормативному техническому состоянию.

Пподобное дополнение в ст.6 рассматриваемого Закона помогло бы снять многие проблемы, в том числе и связанные с состоянием российских дорог в целом. 
DOI: $10.7256 / 1811-9018.2015 .8 .15917$

При цитировании этой статьи сноска на ооі обязательна

\section{Право и политика 8 (188) 2015}

Глава 3 Закона посвящена вопросам дорожной деятельности. В статье 15 определено, что осуществление дорожной деятельности в отношении автодорог общего пользования обеспечивается:

- для автодорог федерального значения - федеральным органом исполнительной власти, осуществляющим функции по оказанию государственных услуг и управлению государственным имуществом в области дорожного хозяйства.

- для автодорог регионального или межмуниципального значения - уполномоченными органами исполнительной власти субъектов РФ.

- для автодорог местного значения - уполномоченным органом местного самоуправления. Тем самым подтверждается вывод о том, что единого управления дорожной сетью страны в Российской Федерации нет. Законом совершенно не учитывается специфика дорожного хозяйства, как отрасли, обеспечивающей единство страны, возможность функционирования ее экономики, что является невозможным без надежной, единой транспортной инфраструктуры, необходимой не только для решения общегосударственных задач (развития экономики, обеспечения обороноспособности страны и т.д.), но и крайне необходимую в век автомобилизации каждому ее гражданину.

Необходимо отметить и то, что в Законе нет положений, предусматривающих обязательность планирования мероприятий, направленных на обеспечение безопасности дорожного движения, приведение дорог в нормативное состояние, на обязательность обеспечения связи всех населенных пунктов с сетью автодорог общего пользования и т.д.

В статью о планировании дорожной деятельности должны быть включены конкретные положения об обязанности планирования мероприятий по приведению сети дорог в состояние, отвечающее нормативно-техническим требованиям, по обязательности планирования мероприятий, направленных на обеспечение надежной, постоянной транспортной связью всех населенных пунктов Российской Федерачии с сетью дорог общего пользования.

Статьи 16, 17, 18 Закона посвящены вопросам проектирования, строительства, ремонта, капитального ремонта, реконструкции и содержания автомобильных дорог. В них определены состав и содержание проектной документации, порядок выдачи разрешений на строительство, реконструкцию и капитальный ремонт автодорог. При этом определено, что классификация работ по капитальному ремонту, ремонту и содержанию автодорог устанавливается федеральным органом исполнительной власти, осуществляющим функции по выработке государственной политики и нормативно-правового регулирования в сфере дорожного хозяйства России.( в настоящее время Минтрансом РФ), а порядок ремонта и содержания автодорог, в зависимости от их значения, соответствующими органами власти. Интересно то, что Законом определено, что работы по ремонту и капитальному ремонту автодорог осуществляются в случае не соответствия их транспортно-эксплуатационных характеристик требованиям технических регламентов.

В то же время в Законе не говорится об обязательности приведения дорог в состояние соответствующее действующим нормам и о мерах, которые необходимо предпринимать при неисполнении Закона, т.е. в случае не приведения дорог в соответствующее нормам состояние.

В связи с этим предлагается ст. 11.16 изложить в следующей редакции - после слов «...ликвидация чрезвычайных ситуачий на автомобильных дорогах» продолжить «в т.ч. ликвидация недоремонта автомобильных дорог с иелью их приведения в нормативное состояние...» и далее по тексту.

При этом обязанность исполнения полномочий, предоставленных органам исполнительной власти в сфере дорожной деятельности, предлагается установить по следующим измененным и дополнительно предлагаемым автором статьям Закона:

11.1 определение основных направлений государственной политики в области использования автомобильных дорог и осуществления дорожной деятельности с конкретизаиией иелей по развитию, совершенствованию и приведению в нормативное состояние сети автодорог общего пользования, в том числе платных автомобильных дорог; 11.2 установление общих требований к осуществлению контроля и осуществление самого контроля в ходе обеспечения сохранности дорог от правонарушений, совершаемых государственными органами управления дорогами, пользователями дорогами, эксплуатирующими организациями, а также иными физическими и юридическими лицами; 11.10 осуществление дорожной деятельности с иелью реализации основных направлений государственной политики по развитию, совершенствованию сети автомобильных дорог и ее содержанию в состоянии, соответствующем требованиям нормативно-технических документов;

11.17 обеспечение пользователей автомобильными дорогами общего пользования объективной информа- 
иией об интересующих их марирутах передвижения, состоянии дорог в т.ч. о допустимых максимальных безопасных скоростях движения на участках дорог с техническими показателями (ровностью, коэффициентом сиепления и т.д.) ниже нормативных;

11.22 разработка программ стратегических научных исследований в сфере дорожного хозяйства, обеспечивающих:

- повышение эффективности правового обеспечения дорожного хозяйства;

- повышение эффективности управления дорожным хозяйством;

- создание системы адекватного финансирования дорожной деятельности;

- снижение ресурсоемкости дорожного производства, стоимости

строительства и эксплуатации автомобильных дорог;

- повышение межремонтных и общих сроков службы автомобильных дорог и дорожных сооружений.

11.23 обеспечение реализации программ стратегических научных исследований в сфере дорожного хозяйства.

Установление в Законе обязательности исполнения органами государственной власти в области использования автодорог и осуществления дорожной деятельности определенных, предоставленных им полномочий, предопределяет необходимость включения в Закон дополнительных статей по установлению ответственности за неисполнение или некачественное исполнение этих полномочий. Что в свою очередь позволяет квалифицировать неисполнение или некачественное исполнение органами государственной власти возложенных на них полномочий, при осуществлении дорожной деятельности, как административные правонарушения и привлекать виновных лиц к соответствующей ответственности, включая и их дисквалификацию.

Кроме того в статью 14 Закона, посвященную планированию дорожной деятельности предлагается ввести дополнительный пункт (14.2) в следующей редакции: «Планирование мероприятий по приведению дорог 6 состояние, отвечающее требованиям нормативнотехнических документов, обеспечивающее устранение неблагоприятных дорожных условий, влияющих на безопасность дорожного движения, является приоритетным при планировании дорожной деятельности».

Конкретному решению этих проблем в Законе должно быть уделено особое место.

По главе 4 Закона, определяющей особенности использования земельных участков, предназначенных для размещения автомобильных дорог имеются особые замечания, связанные с резервированием земель под дорожные нужды. В настоящее время сложилась ситуация, когда на выкуп земель из частной собственности уходят огромные деньги (до $30 \%$ от стоимости объектов).

В действующем законодательстве не решен вопрос предотвращения спекуляции земельными участками. В связи с тем, что для обеспечения строящихся дорог необходимы огромные площади, ущерб который несет государство от неэффективного правового решения данного вопроса, так же огромен. Без сомнения, данная глава нуждается в существенной доработке и включении дополнительных статей, обеспечивающих эффективность решения имеющихся проблем;

Нельзя не отметить недоработки пятой главы, в которой рассмотрены права и обязанности пользователей дорог.

В первую очередь хотелось бы отметить чисто стилистические ошибки:

- в п.1 Ст. 28 говорится о том, что пользователи дорог имеют право получать компенсацию вреда причиненного их жизни ...»

данное право предлагается вынести в спещииальный раздел ст. 28 в редакичии:

Родственники пользователей автомобильных дорог имеют право получать компенсаиию вреда, причиненного жизни пользователей дорог (далее по тексту п.2 cm. 28).

- в п.3 ст.28 говорится о том, что пользователи дорог имеют право «получать информацию о маршрутах транспортных средств по автомобильным дорогам...». Вполне законно возникает вопрос - о каких именно маршрутах идет речь?

предлагается следующая формулировка:

«пользователи автомобильных дорог имеют право получать оперативную информачию об интересующих их маршрутах транспортных средств по автомобильным дорогам...» и далее по тексту.

Статью 29 под названием «Обязанности пользователей автомобильными дорогами и иных лиц, осуществляющих использование автомобильных дорог» для большей ясности стоит переименовать в «Запрещающие меры для пользователей автомобильными дорогами и иных лиц, осуществляющих использование автомобильных дорог». В противном случае не совсем понятно что обязаны делать лица, осуществляющие использование автомобильных дорог, т.к. конкретного пункта, посвященного установлению перечня обязанностей данная статья неимеет. Также хотелось бы обратить внимание 
DOI: $10.7256 / 1811-9018.2015 .8 .15917$

При цитировании этой статьи сноска на ооі обязательна

\section{Право и политика $8(188) \cdot 2015$}

на то, что в состав статьи 29 не включен ряд норм, предотвращающих повреждение автомобильных дорог:

В п.1.1 ст. 29, запрещающем пользователям автомобильных дорог «осуществлять движение по автомобильным дорогам на транспортных средствах, имеющих элементы конструкций, которые могут нанести повреждения автомобильной дороге», предлагается внести изменения: «... на транспортных средствах имеющих элементь собственных конструкиий или конструкиий перевозимых грузов, которые могут нанести повреждения автомобильной дороге...»

Подобное изменение в тексте статьи обусловлено прежде всего тем, что элементы конструкций, способных повредить автомобильную дорогу, могут быть не только у самого специально оборудованного транспортного средства, но также и у перевозимого им груза. При отсутствии такой конкретизации нарушение может трактоваться двояко.

В связи с тем, что нарушения в сфере дорог могут совершать не только лица, осуществляющие пользование дорогами, название п2. Ст.29 «Пользователям автомобильными дорогами и иным лицам, осуществляющим использование автомобильных дорог запрещается: » предлагается изменить в следующей редакции:

«Пользователям автомобильными дорогами, $u$ иным юридическим и физическим лицам запрещяается:»

В п.2.1. запрещающий «пользователям дорог и иным осуществляющим использование дорог лицам загрязнять дорожное покрытие, полосы отвода и придорожные полосы, откосы автомобильных дорог» предлагается внести изменения:

после слов «...загрязнять дорожное покрытие» продолжить «обочины, oткосы...» и далее по тексту.

Такое изменение позволит предотвратить не только загрязнение самой проезжей части, но и обочин, которые на большинстве дорог Российской Федерации не имеют покрытия.

В п.2.2. запрещающий «использование водоотводных сооружений для сброса или стока вод» предлагается внести следующие изменения:

«... для стока или сброса вод и других жидкостей, а также веществ, которые могут оказать отрииательное влияние на экологию и безопасность дорожного движения»

Такое изменение обусловлено тем, что в водоотводные сооружения могут сливаться бытовые отходы, отработанные масла и т.д., которые не входят в перечень запрещенных для слива средств, однако способны причинить существенный вред не только безопасности дорожного движения, но и самой дороге и окружающей среде.

В п.2.3 запрещающий «выполнять в границах полос отвода автомобильных дорог, в том числе на проезжей части автомобильных дорог, работы, связанные с применением горючих веществ, а также веществ, которые могут оказать воздействие на уменьшение сцепления колес транспортных средств с дорожным покрытием» предлагается внести изменения:

после слов «...в том числе» продолжить «на проезжей части, обочинах, откосах автомобильных дорог, работы, связанные с применением горючих веществ...» и далее по тексту.

Такое изменение обусловлено тем, что нарушения могут быть совершены не только по причине ведения работ, но и по иным причинам (отдых, хулиганство и т.д.), и совершены они могут быть не только на проезжей части, но и на других ее конструктивных элементах (обочинах, откосах). Последствиями подобных нарушений могут быть не только снижение эффективности сцепления, но и возникновение дефектов и разрушений, отрицательно влияющих на безопасность дорожного движения, на любом из указанных элементов дороги.

Необходимо отметить, что положения 4), 6) и 7) в пункте 2 ст. 29 носят достаточно общий, декларативный характер, что в общем оставляет неоднозначное мнение о статье в целом и позволяет сделать вывод о необходимости ее переработки или доработки.

Глава 6 посвящена финансированию дорожной деятельности. Законом определено, что дорожная деятельность в отношении автодорог общего пользования, в зависимости от их значимости, осуществляется за счет средств:

- федерального бюджета (дороги федерального значения)

- бюджетов субъектов РФ (дороги регионального и межмуниципального значения)

- местных бюджетов (дороги местного значения).

Финансирование дорожного хозяйства из бюджетов всех уровней привело к резкому снижению объемов финансирования дорог. Только в период с 2000 по 2004 годы объем финансирования снизился с 2,9\% ВВП до $1,4 \%$ ВВП $[5,6]$. В результате из-за недостатка финансирования в значительной части регионов выполняемые работы по строительству и эксплуатации дорог сведены к недопустимому минимуму. В свою очередь, не выполнение ежегодных ремонтно-восстановительных работ, обусловленных износом дорог, без сомнения приведет к резкому увеличению расхода финансовых ресурсов на восстановление дорожной сети в последу- 
ющие периоды. Из-за недостаточности финансирования произошло сокращение и приостановка строительства и реконструкции ряда крайне важных и эффективных для экономики страны дорожных проектов.

С учетом этих фактов, а также с учетом не только зарубежного, но и собственного российского положительного опьта, имеющихся научных исследований, целесообразно произвести изменение системы финансирования дорожного хозяйства, путем создания цуелевых внебюджетных фондов, подключения к их формированию и управлению пользователей дорог, что и должно быть отражено в главе 6 рассматриваемого Ф3.

Не смотря на то, что финансирование дорог в России в настоящее время осуществляется из бюджетов, т.е. из обезличенных средств - фактическое финансирование дорог в значительной мере ведется за счет налогов, перечисляемых пользователями дорог (физическими и юридическими лицами).

В связи с этим, возможности их воздействия на состояние дорожного хозяйства должны быть более обширными и реальными. Ведь именно пользователи, больше чем кто либо, заинтересованы в улучшении состояния дорог, адекватном их финансировании, повышении эффективности использования средств, выделяемых на развитие и улучшение состояния сети дорог общего пользования.

Особого внимания в главе 7 Закона заслуживает широко рекламируемая органами власти идея развития в России платных автомобильных дорог.

При этом критических замечаний, заслуживают положения Закона, устанавливающие: обязательность обеспечения альтернативного бесплатного проезда и систему финансирования строительства платных дорог.

Определенное Законом решение по обеспечению альтернативного бесплатного проезда, протяженностью не превышающем более, чем в три раза протяженность платного участка дороги, можно считать приемлемым при новом строительстве такого платного участка. Однако при реконструкции существующей дороги, ранее построенной за счет бюджетных средств (создаваемых пользователями дорог - физическими и юридическими лицами), протяженность альтернативного участка проезда не должна превышать протяженность участка платной дороги более чем в полтора раза. Анализ имеющейся зарубежной практики и оценка экономической целесообразности устройства таких объектов подтверждает приемлемость именно этой величины. Принципиальным в Законе должно быть положение, определяющее обязательность строительства (реконструкции) платных автомобильных дорог за счет частных инвестиций, государство же должно выступать гарантом в данных отношениях.

Являясь юридической основой административно-правового регулирования дорожного хозяйства Российской Федерации, Федеральный закон «Об автомобильных дорогах и дорожной деятельности в Российской Федерации» обеспечил установление обязательных требований к автомобильным дорогам и дорожной деятельности и правовое решение многих из задач, стоящих перед дорожной отраслью.

Однако, основным показателем эффективности действующего законодательства всегда является его реальное влияние на практику, в нашем случае - не состояние дорожной сети страны, которое практически не улучшилось за прошедший период его действия.

Данный факт позволяет говорить о существенных недочетах, допущенных в первую очередь при разработке и принятии Федерального закона «Об автомобильных дорогах и дорожной деятельности...».

К основным из них следует о отнести:

- решение о финансировании дорожной деятельности за счет средств бюджета (имеющаяся российская практика доказывает малую эффективность этого способа финансирования);

- решение, законодательно закрепляющее разделение дорожной сети страны на фрагменты (самостоятельные сети дорог) - федеральную, региональные и муниципальные, состоянием и развитием которых ответственные субъекты должны заниматься самостоятельно, без увязки с развитием общей сети страны;

- отсутствие положений, устанавливающих ответственность руководителей органов управления дорожным хозяйством за развитие и состояние подведомственных им сетей дорог общего пользования;

- отсутствие положений, предусматривающих подключение к процессу управления и финансирования дорожного хозяйства пользователей автомобильных дорог;

- отсутствие в числе основных понятий таких как: дорожное хозяйство, сеть автомобильных дорог и т.д.;

- недостаточно корректные определения данные таким основным понятиям как: автомобильные дороги, дорожная деятельность и т.д.

Все перечисленное, позволяет с одной стороны говорить о том, что Федеральный закон «Об автомобильных дорогах и дорожной деятельности» №257-Ф3 от 8.11.2007 стал юридической основой административно-правового регулирования дорожного хозяйства, а с другой стороны - о необходимости его корректировки и доработки с целью повышения эффективности его воздействия на общественные отношения в сфере дорожного хозяйства. 
DOI: $10.7256 / 1811-9018.2015 .8 .15917$

При цитировании этой статьи сноска на dоі обязательна

\section{Право и политика $8(188) \cdot 2015$}

\section{Библиография:}

1. Отчет о состоянии федеральных автомобильных дорог. - М.: Росдорнии. -2009 г. -317 с.

2. Verkehr in Zahlen. DIW. Berlin, 2005. - 57s

3. Табаков Н. В., Кретов В.В. Анализ нормативно-правового обеспечения дорожной деятельности Российской Федерации. //Право и политика. М., 2013. - №4. - c. 23-31

4. Jahre Strassenwesen in der Bundesrepublik Deutschlan. Bonn, December 2000. - 73s.

5. Дорожное хозяйство России цифры и факты. - М.: Росавтодор, 2003г. -325 с.

6. Дорожное хозяйство России цифры и факты. - М.: Росавтодор, 2006г. - 350 с.

\section{References (transliterated):}

1. Verkehr in Zahlen. DIW. Berlin, 2005. - 57s.

2. 3. Tabakov N. V., Kretov V.V. Analiz normativno-pravovogo obespecheniya dorozhnoi deyatel'nosti Rossiiskoi Federatsii. //Pravo i politika. M., 2013. - №4. - s. 23-31

3. Jahre Strassenwesen in der Bundesrepublik Deutschlan. Bonn, December 2000. - 73s. 